NASA/TM-2002-211795

IECEC-2002-20161

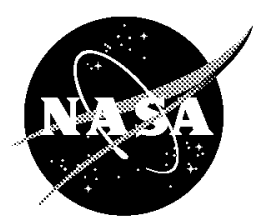

\title{
Estimator Based Controller for High Speed Flywheel Magnetic Bearing System
}

Timothy P. Dever

QSS Group, Inc., Cleveland, Ohio

Gerald V. Brown

Glenn Research Center, Cleveland, Ohio

Ralph H. Jansen

Ohio Aerospace Institute, Brook Park, Ohio 
The NASA STI Program Office ... in Profile

Since its founding, NASA has been dedicated to the advancement of aeronautics and space science. The NASA Scientific and Technical Information (STI) Program Office plays a key part in helping NASA maintain this important role.

The NASA STI Program Office is operated by Langley Research Center, the Lead Center for NASA's scientific and technical information. The NASA STI Program Office provides access to the NASA STI Database, the largest collection of aeronautical and space science STI in the world. The Program Office is also NASA's institutional mechanism for disseminating the results of its research and development activities. These results are published by NASA in the NASA STI Report Series, which includes the following report types:

- TECHNICAL PUBLICATION. Reports of completed research or a major significant phase of research that present the results of NASA programs and include extensive data or theoretical analysis. Includes compilations of significant scientific and technical data and information deemed to be of continuing reference value. NASA's counterpart of peerreviewed formal professional papers but has less stringent limitations on manuscript length and extent of graphic presentations.

- TECHNICAL MEMORANDUM. Scientific and technical findings that are preliminary or of specialized interest, e.g., quick release reports, working papers, and bibliographies that contain minimal annotation. Does not contain extensive analysis.

- CONTRACTOR REPORT. Scientific and technical findings by NASA-sponsored contractors and grantees.
- CONFERENCE PUBLICATION. Collected papers from scientific and technical conferences, symposia, seminars, or other meetings sponsored or cosponsored by NASA.

- SPECIAL PUBLICATION. Scientific, technical, or historical information from NASA programs, projects, and missions, often concerned with subjects having substantial public interest.

- TECHNICAL TRANSLATION. Englishlanguage translations of foreign scientific and technical material pertinent to NASA's mission.

Specialized services that complement the STI Program Office's diverse offerings include creating custom thesauri, building customized data bases, organizing and publishing research results... even providing videos.

For more information about the NASA STI Program Office, see the following:

- Access the NASA STI Program Home Page at http://wwo.sti.nasa.gov

- E-mail your question via the Internet to help@stinasa.gov

- Fax your question to the NASA Access Help Desk at 301-621-0134

- Telephone the NASA Access Help Desk at 301-621-0390

- Write to: NASA Access Help Desk NASA Center for AeroSpace Information 7121 Standard Drive Hanover, MD 21076 


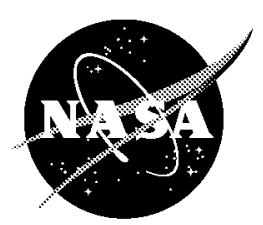

\section{Estimator Based Controller for High Speed Flywheel Magnetic Bearing System}

Timothy P. Dever

QSS Group, Inc., Cleveland, Ohio

Gerald V. Brown

Glenn Research Center, Cleveland, Ohio

Ralph H. Jansen

Ohio Aerospace Institute, Brook Park, Ohio

Prepared for the

37th Intersociety Energy Conversion Engineering Conference

sponsored by the Institute of Electrical and Electronics Engineers, Electron Devices Society

Washington, DC, July 28-August 2, 2002

National Aeronautics and

Space Administration

Glenn Research Center 
Available from

NASA Center for Aerospace Information 7121 Standard Drive

Hanover, MD 21076
National Technical Information Service 5285 Port Royal Road Springfield, VA 22100

Available electronically at http://glrs.grcnasa.gov 


\title{
Estimator Based Controller For High Speed Flywheel Magnetic Bearing System
}

\author{
Timothy P. Dever \\ QSS Group., Inc. \\ Cleveland, Ohio 44135 \\ 216-433-2384 \\ E-mail: timothy.p.dever@grc.nasa.gov \\ Gerald V. Brown \\ National Aeronautics and Space Administration \\ Glenn Research Center \\ Cleveland, Ohio 44135 \\ 216-433-6047 \\ E-mail: gerald.v.brown@grc.nasa.gov \\ Ralph H. Jansen \\ Ohio Aerospace Institute \\ Brook Park, Ohio 44142 \\ 216-433-6038 \\ E-mail: ralph.h.jansen@grc.nasa.gov
}

\begin{abstract}
A flywheel system and its operator interface are described. Measurements of magnetic bearing negative stiffness are performed. Two digital magnetic bearing control algorithms (PD and estimator based) are defined, and their implementations are described. Tuning of each controller is discussed. Comparison of the two controllers' stability, damping noise and operating current are described. Results describing the superiority of the estimator-based controller are presented and discussed.
\end{abstract}

\section{INTRODUCTION}

Flywheel systems for energy storage and attitude control are being developed at NASA Glenn Research Center (GRC) in Cleveland, Ohio. Flywheels show promise as an alternative to batteries and reaction wheels for space systems. Strengths of this technology include high energy density, long life, $90 \%$ depth of discharge, and pulse power capability. A system level flywheel test bed is operational at GRC; the flywheel module under test is called the High Speed Shaft (HSS).

The HSS module uses a motor/generator coaxial with the rotor to facilitate energy storage and retrieval. Active magnetic bearings (AMBs) are used to provide a long-life, low-loss suspension of the rotor. This paper focuses on two magnetic bearing control algorithms used to levitate the HSS rotor; a PD controller and an improved, estimator-based controller. Development and implementation of both controllers is described. Test data is presented, describing the improvements provided by use of the estimator. Using the estimator controller, the HSS has been successfully spun to 58,000 RPM.

\section{SYSTEM AND MODULE CONFIGURATION}

An overall HSS system configuration schematic is shown in Figure 1. Two separate controllers are used to control the HSS: a motor/generator controller, and a magnetic bearing controller. Both controllers are written using a commercially available high level simulation/control tool, which generates $\mathrm{C}$ code, and executes on a PC based control card.

The motor/generator (M/G) controller allows control of the motor speed using a novel sensorless algorithm; control commands are converted to motor currents by the M/G inverter. The magnetic bearing (MB) controller generates control signals which are converted to bearing currents by the MB pulse-widthmodulated (PWM) power amplifier system; position sensor signals are processed by the sensor subsystem, and fed back to the MB controller.

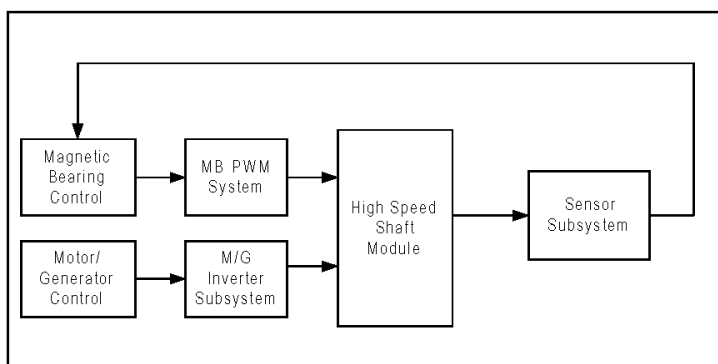

Figure 1. HSS System Configuration Schematic

The HSS flywheel module is shown schematically in Figure 2. The main components of the module are the rotor, motor/generator, magnetic bearings, touchdown bearings, and housing. The rotor is a 
metal shaft which is 3 " in diameter at the center, and about 1.5" diameter elsewhere. The MB system used to levitate the rotor is a five-axis system. Shaft location for the five axes is determined using noncontact eddy current sensors. The bearing and sensor axes are defined as $X 1, Y 1$ (bottom radial direction), $X 2$ and $Y 2$ (top radial direction), and $Z$ (axial direction). When the MB system is not activated, the shaft rests on rolling element touchdown bearings located at the top and bottom of the system. Because the shaft can heat up and expand axially, axial growth is monitored during operation; this is achieved using the growth sensor at the bottom of the unit in conjunction with the $Z$ sensor. Also, a tachometer (or one per revolution) signal is generated for use in the bearing code by a pair of sensors near the top of the unit.

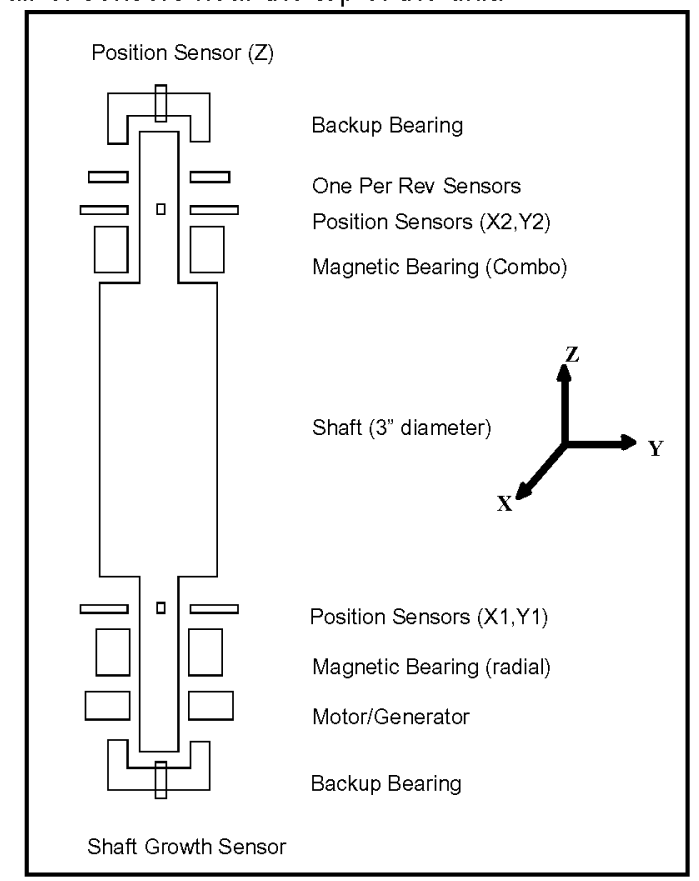

Figure 2. HSS Module Schematic

A simplified schematic of one axis of the MB control loop is shown schematically in Figure 3. The bearing control code in the AMB controller generates command signals to allow shaft levitation. These command signals are converted to drive currents by the pulse width modulated (PWM) amplifiers. These currents are fed to the MB actuators; forces produced by the actuators suspend the rotor. The position of the rotor is measured using non-contact eddy current sensors; these sensor signals are processed by the signal conditioning system and fed back to the bearing controller as input to the MB control algorithm.

The MB controller is a closed loop control system, however, an operator is present whenever the system is in use. The operator can make changes to bearing controller tuning while operating, if necessary; however, under typical operating conditions, the bearing control is automatic. Key elements of the MB operator console include the shaft position display, the bearing current display, the position and current spectral display, and the operator human-machine interface (HMI).

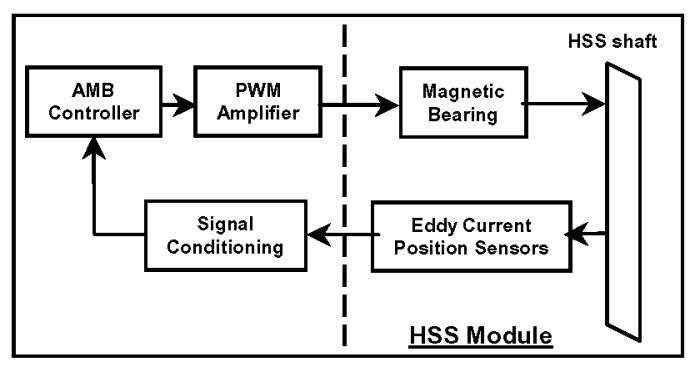

Figure 3. Simplified MB Control System

The shaft position display is shown schematically in Figure 4. Three oscilloscopes are used to provide operator feedback on the position of the flywheel shaft.

Radial clearance is displayed graphically on an X$Y$ plot generated on oscilloscopes. A circle describing the allowable range of travel of the shaft (defined by the clearance of the backup bearings) is stored in scope memory and continually displayed. Simultaneously, the present center of the shaft (from the $X$ and $Y$ position sensor outputs) is displayed in real time as a dot on the scope. Separate scopes are used to display top and bottom radial shaft position.

Axial clearance is provided by a third oscilloscope run in standard X-T mode. Two cursors mark the top and bottom of the travel allowed by the backup bearings, while the present location of the shaft, determined by the $Z$ position sensor output, is displayed in real time as a trace on the scope.

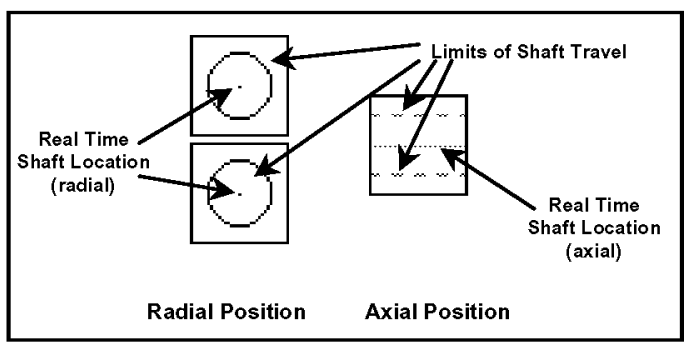

Figure 4. MB Operator Console - Shaft Position

Bearing current displays are in the same format as the position displays. Current sensors monitoring each bearing axis are scaled and plotted on oscilloscopes in an X-Y plot for radial MB currents and an X-T plot for the axial MB current.

Spectral plots display the same information as the position and current displays; one plot displays all five axis positions versus frequency, and the other plot displays current for all five axes versus frequency, in real time.

The operator $\mathrm{HMl}$ allows for adjustment of control law gains during operation. 


\section{1-D MAGNETIC BEARING MODEL}

The HSS magnetic bearing actuators include permanent magnets to provide bias flux, and electromagnets to provide control flux. With the electromagnets turned off, the actuator can be represented by a mass-spring system, where the spring has a negative stiffness provided by the permanent magnets. The force diagram for a rigid body in a magnetic bearing with permanent magnets is shown in Figure 5.

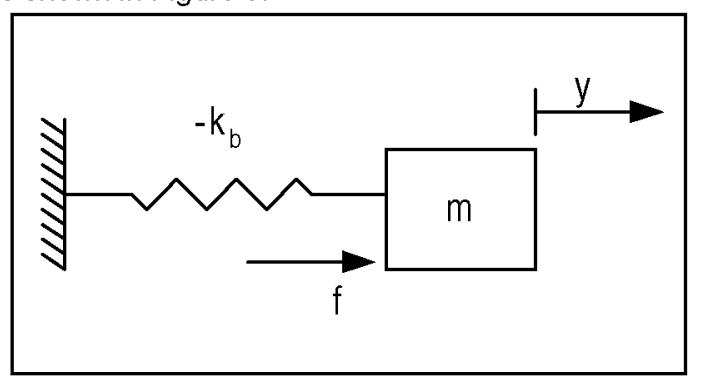

Figure 5. Bearing Actuator Force Diagram

The equation of motion for the actuator is

$$
m \ddot{y}-K_{b} y=f
$$

Taking the Laplace transform and solving gives the transfer function

$$
\frac{Y(s)}{F(s)} \equiv G(s)=\frac{1}{m s^{2}-K_{b}}
$$

The poles for this system are $\pm \sqrt{\mathrm{K}_{\mathrm{b}} / \mathrm{m}}$, making the system unstable; compensation must be added to stabilize the system.

Ideally, the compensator would allow the magnetic bearing to have a positive, tunable stiffness in place of the negative stiffness. Also, since the system as-is provides no damping, the controller should provide a tunable damping force as well.

Shaft position is measured directly by the position sensors. Unfortunately, sensors that directly measure velocity are not practical, so our velocity term must come from another source. The first obvious bearing controller solution is a PD controller, which acquires the shaft velocity from the position derivative. The PD controller transfer function is

$$
\mathrm{H}(\mathrm{s})=\mathrm{cs}+\mathrm{k}
$$

The closed loop transfer function of the PD controller implemented as a cascade compensator for the MB actuator can be written in the form

$$
\mathrm{G}_{\mathrm{cl}}=\left[\frac{\mathrm{c}}{\mathrm{m}}\right]\left[\frac{\mathrm{s}+\frac{\mathrm{k}}{\mathrm{c}}}{\mathrm{s}^{2}+\frac{\mathrm{c}}{\mathrm{m}} \mathrm{s}+\frac{\mathrm{k}-\mathrm{K}_{\mathrm{b}}}{\mathrm{m}}}\right] .
$$

Note that this transfer function has the form of a mass-spring-damper system, as desired. The damping is a function of the controller damping gain and the effective mass of the rotor, and the natural frequency is described as

$$
\omega_{\mathrm{n}}=\sqrt{\frac{\mathrm{k}-\mathrm{K}_{\mathrm{b}}}{\mathrm{m}}}=\sqrt{\frac{\mathrm{K}_{\mathrm{net}}}{\mathrm{m}}} .
$$

Note that the net stiffness of the system is simply the difference between the controller proportional gain and the negative stiffness of the actuator.

The PD controller can be successfully implemented and used to levitate the flywheel shaft. However, this approach has a major drawback. Noise present in the position sensor signal is increased by use of its derivative; this degrades the quality of the control provided by the PD. Although low pass filtering can be added to the sensor signals to reduce high frequency noise, this filtering also adds phase lag to the system, which is undesirable. An alternate approach is to develop an estimator of the plant, and use the estimator to generate the velocity term for controller damping. Implementation and testing of the estimator-based controller (as well as the PD controller) are described in the next sections.

\section{DETERMINING NEGATIVE STIFFNESS}

We know from (5) that the net stiffness of the compensated $\mathrm{MB}$ is proportional to its natural frequency squared. We can use this relationship to measure the bearing negative stiffness. To do so, the flywheel was first levitated using the PD controller. Next, damping for the axis under test was decreased until the shaft began to oscillate, and the oscillation frequency was measured. This process was repeated over a range of stiffness values. Oscillation frequency squared is then plotted versus controller stiffness; Figure 6 displays this data for all four radial bearings. $K_{n e t}$ is the sum of Kcontrol and the bearing negative stiffness (the shaft becomes unstable when this sum falls to zero), and the negative stiffness for the bearings can be read directly from the $X$-axis intercept. Note the excellent agreement between the two axes of a given bearing. 


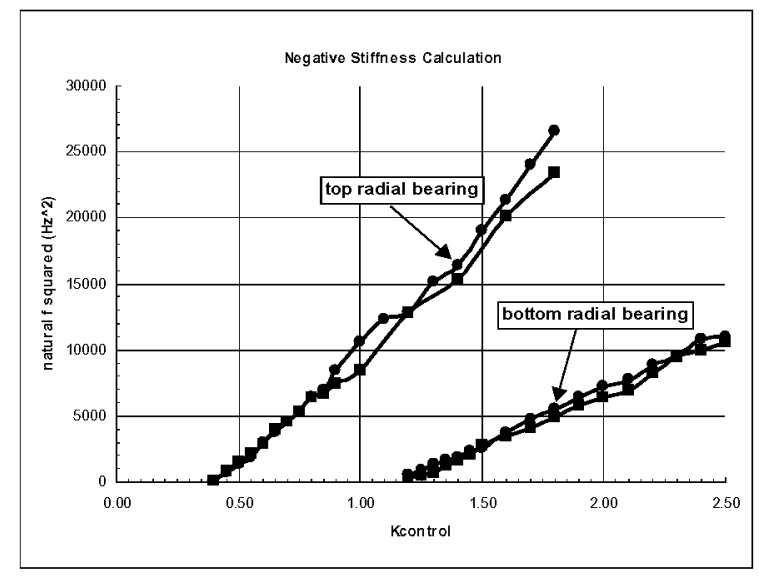

Figure 6. Negative Stiffness Measurement

\section{PD IMPLEMENTATION AND TUNING}

Both the PD and estimator controller designs use a decentralized control approach; that is, each axis is treated separately from all of the others. For the purposes of this discussion, we will simply describe the controller for a single axis.

The PD implementation is shown in block diagram form in Figure 7. The PD block is used as a cascade compensator.

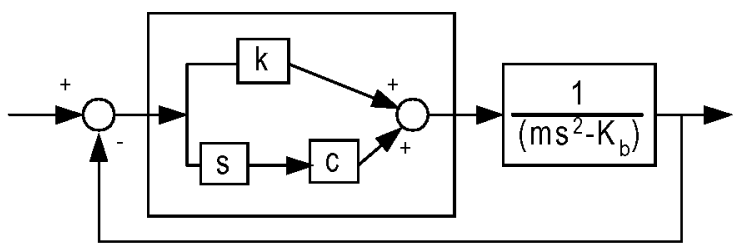

Figure 7. PD Controller Implementation

The PD controller was tuned by first selecting $K_{\text {net }}$, which is the desired net stiffness for the compensated MB. The net stiffness is often set equal to the negative stiffness of the weaker bearing; in this case, use of this rule of thumb provided an excellent choice for $\mathrm{K}_{\text {net. }}$ Next, the bearing was levitated. A square wave signal was input to the controller, and damping was increased until the noise from the derivative began to impact performance. This left us with a slightly underdamped response.

\section{ESTIMATOR IMPLEMENTATION AND TUNING}

The estimator implementation is shown schematically in Figure 8, where the " $e$ " term is the shaft velocity value as calculated by the estimator. Note the similarity between the control algorithms; for the estimator controller, the derivative is simply replaced by the estimator value. Note also that the controller output is fed back a second input on the estimator.

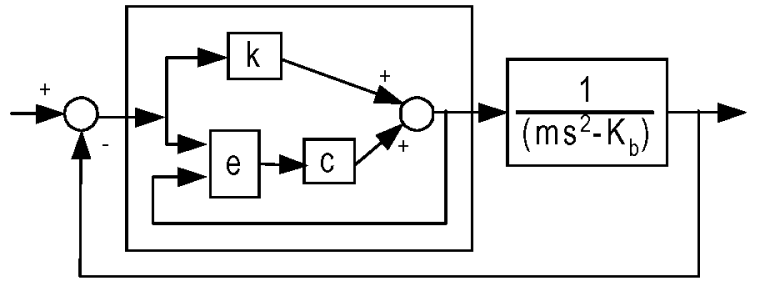

Figure 8. Estimator Controller Implementation

The estimator itself is shown schematically in Figure 9. At the center of the estimator is a model of the compensated magnetic bearing. In this model, the estimated force on the shaft $\left(F_{e}\right)$ is divided by shaft mass $(m)$ to give estimated acceleration $A_{e}$. $A_{e}$ is integrated twice, once to provide estimated velocity $\left(V_{e}\right)$ and again for estimated position $\left(X_{e}\right)$. The two inputs to the model are the controller output signal and the controller/estimator error multiplied by a gain $(\mathrm{kfb})$; these two signals provide the corrections to the estimator force.

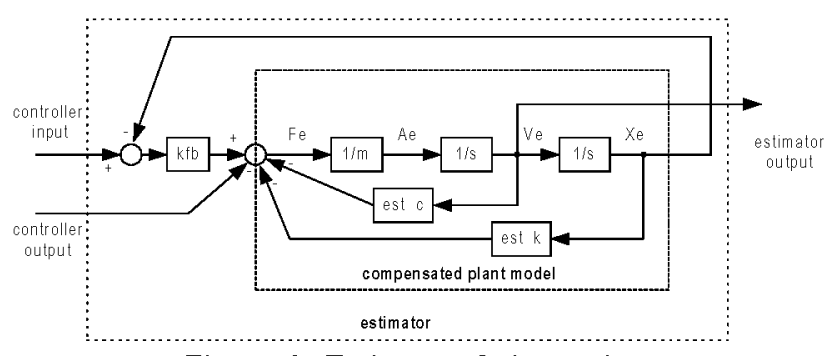

Figure 9. Estimator Schematic

The estimator-based controller was tuned in two steps. The first step was to get a reasonable starting point on the tuning parameters. To do this, the PD controller was used to levitate the shaft, with the estimator running open loop in parallel with the PD. A low frequency sine wave was input to both controllers, and the command signals from both controllers were output to oscilloscopes. The HMI was used to explore the effect of each estimator parameter, and allow tuning on the operating flywheel without risking damage due to unstable behavior. With the same $K_{\text {net }}$ as a starting point, the estimator was tuned until its output command approximated the PD command signal for low frequencies.

Next, the estimator parameters were optimized. Considerable effort was spent minimizing noise in the flywheel system; this effort allowed us to optimize estimator tuning live on the levitated flywheel. Using the initial tuning gains from step one, the flywheel was levitated using only the estimator controller. While monitoring the position and current spectrum display, the estimator parameters were fine-tuned to minimize the noise floor and mode peaking while levitated. As with the PD tuning, this optimization also resulted in a slightly underdamped response, although use of more damping was practical with the estimator due to its superior noise performance. 


\section{PD VERSUS ESTIMATOR PERFORMANCE}

In this section, performance of the PD controller is compared to that of the estimator controller. Stability, damping control effort, and bearing current spectra are compared for the two controller types.

\section{Stability Maps}

The stable operating region of a bearing controller is an important indicator of its performance. This region was measured for both controllers on the levitated flywheel. On the axis under test, the controller damping was lowered until the system became unstable. Next, from the same starting point, the damping was raised until instability was once again reached. This process was repeated for a range of control stiffness, and the stable operating regions were mapped by plotting controller damping instability points versus stiffness. Stability regions for the top and bottom bearings are shown in Figure 10.
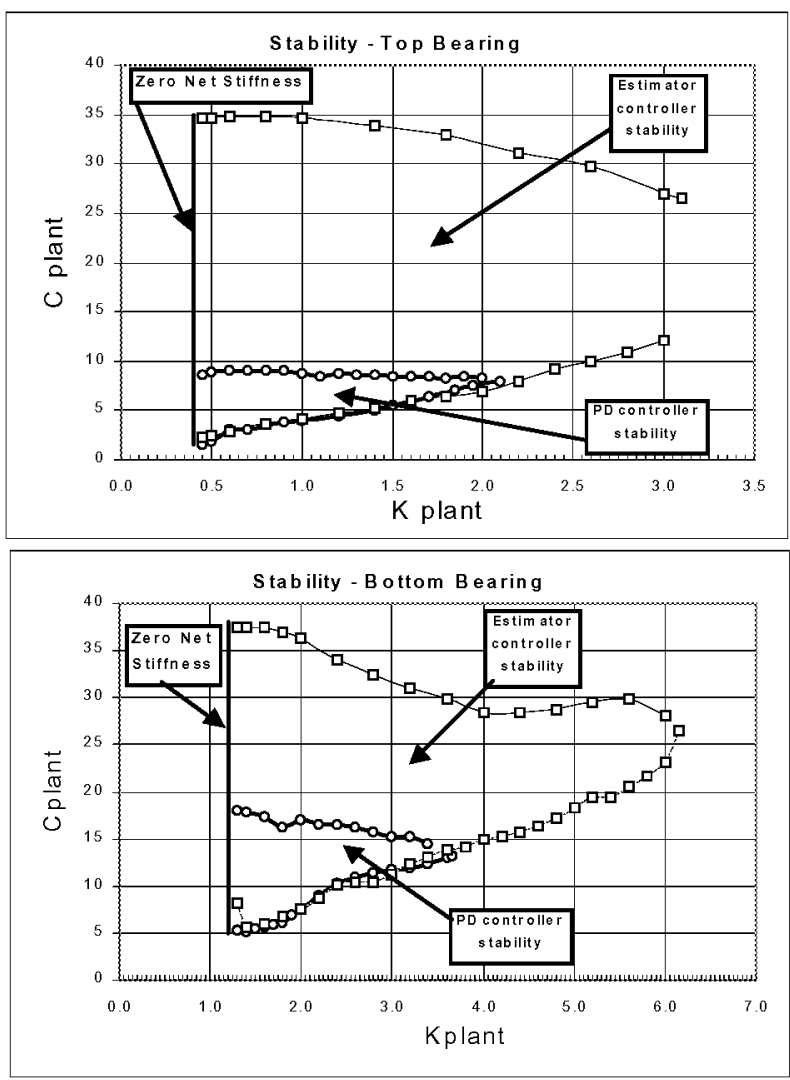

Figure 10. Stability Comparison - Top and
Bottom Bearings

The left end of the stability region is simply the zero net stiffness line - the system is unstable beyond this point. The lower edge of the stability region is the boundary where damping becomes low enough that the flywheel begins to oscillate. In the case of the PD controller, it is suspected that the upper limit on stability arises from saturation or nonlinearity of some component caused by high frequency noise generated by the derivative. The upper boundary for the estimator controller is caused by the higher damping gain driving controller eigenvalues into an unstable range.

Note that the estimator stability region is considerably larger, both for top and bottom bearings. More damping can be applied to the plant with the estimator controller for the same stiffness (due to the lower noise characteristics of the estimator damping), and the estimator can operate at higher stiffness than the PD, if desired. This demonstrates the superior stability performance of the estimator-based controller.

\section{Damping Control Effort}

The estimator controller was developed specifically to improve the quality of the damping control effort, mainly to reduce it. The PD controller uses the derivative of the shaft position signal to generate its damping control signal; the noisy nature of this derivative results in a noise plagued damping signal. This impacts flywheel controllability, as the levitated flywheel cannot be damped adequately without introducing noise.

To measure noise present in the damping control effort, the flywheel was levitated, with a sine wave input to the system, and the damping portion of the control signal (at the summing block in the controller) was stored. This test was done on both the PD and estimator controller. Both controllers were run at the same net stiffness value, and damping for each was optimized.

Figure 11 shows the damping control signal for the PD controller with sine wave input, and Figure 12 shows the same response with the estimator controller, plotted on the same vertical scale. The disturbance was a low frequency sine $(1.5 \mathrm{~Hz})$; this is well within the bandwidth of the MB actuator, and so the flywheel can be moved at this speed. Since the damping control effort should be a response to shaft velocity, ideally the damping portion of the control effort should be sinusoidal. In Figure 12, the estimator damping control is clearly sinusoidal in shape. However, with the PD response in Figure 11, the sine wave is almost undetectable, due to the high frequency noise present in the damping term; there is considerably more noise in the PD damping signal. This clearly demonstrates the superior performance provided by the estimator based damping.

\section{Operating Performance}

The static tests (levitated without spinning) of stability and damping control effort described in the previous sections clearly indicate that the estimator controller is superior to the PD controller. However, the true test of performance is operation while the flywheel is spinning. To measure relative performance of the two controllers while the flywheel is spinning, bearing current spectral measurements were used. 


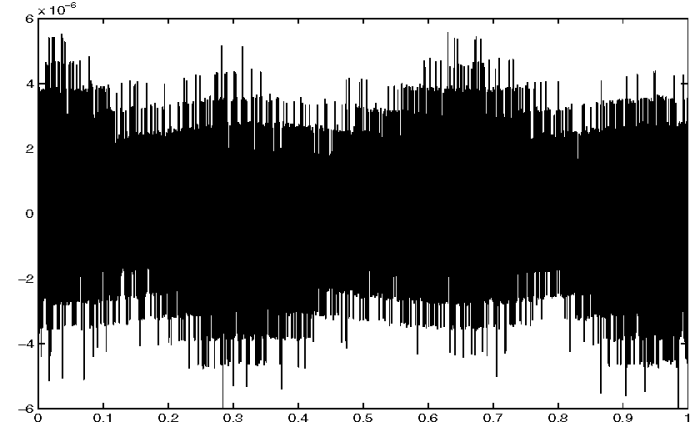

Figure 11. PD Control Effort to Sinusoidal Input

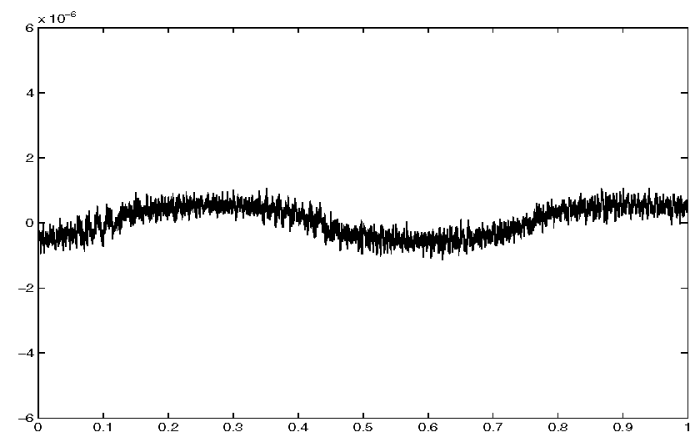

Figure 12. Estimator Control Effort to Sinusoidal Input

During normal flywheel operation, position and $\mathrm{MB}$ current signals are run to a spectrum analyzer, and displayed in real time. In order to compare the relative performance of the controllers, spectra of the control currents were averaged and stored. Figures 13 and 14 show the time averaged MB current for the flywheel module while levitated and spinning at 20,000 RPM

If the multiples of $60 \mathrm{~Hz}$ noise and synchronous spin frequency (at 20KRPM, this is $333 \mathrm{~Hz}$ ) are ignored, we see that the maximum control effort exerted by the estimator is an order of magnitude lower than that for the PD controller. In addition, at the higher displayed frequencies, the reduction in control effort is even greater.

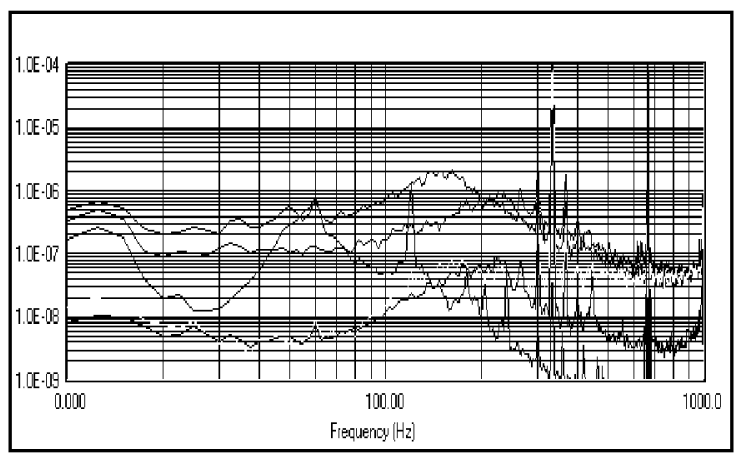

Figure 13. PD MB Control Current Spectrum

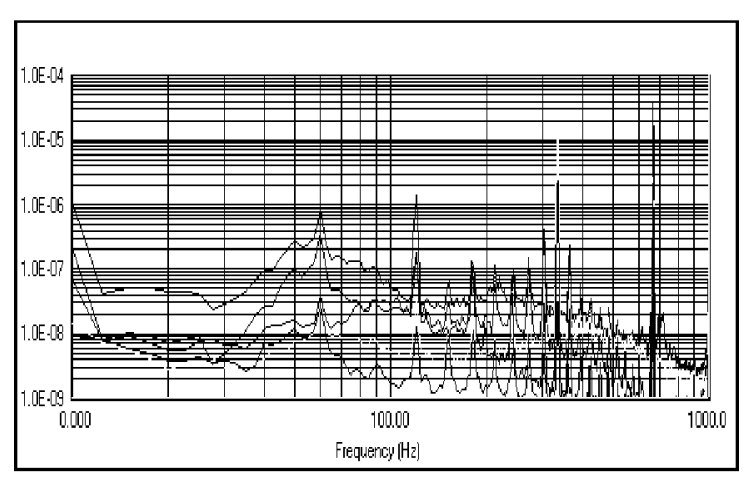

Figure 14. Estimator MB Control Current Spectrum

\section{CONCLUSIONS}

Experimental testing on the flywheel system demonstrated the superior performance of the estimator-based controller over the PD controller.

The estimator was developed to provide a low noise damping control effort for the flywheel. Stability maps for the two controllers show a much larger stable operating region, translating to greater allowable stiffness and damping values with the estimator controller. Examining the damping portion of the control effort shows that the estimator is considerably less noisy that the PD. In addition, due to the improved noise performance, the control effort required to levitate the flywheel while spinning is greatly reduced with the estimator.

\section{REFERENCES}

Knospe, C.R. and Maslen, E.H., 1999 , "Introduction to Active Magnetic Bearings," Short course presented at NASA Glenn Research Center.

Schweitzer, G., Blueler, H. and Traxler, A., 1994, "Active Magnetic Bearings," vdf Hochschulverlag AG and ETH, Zurich. 


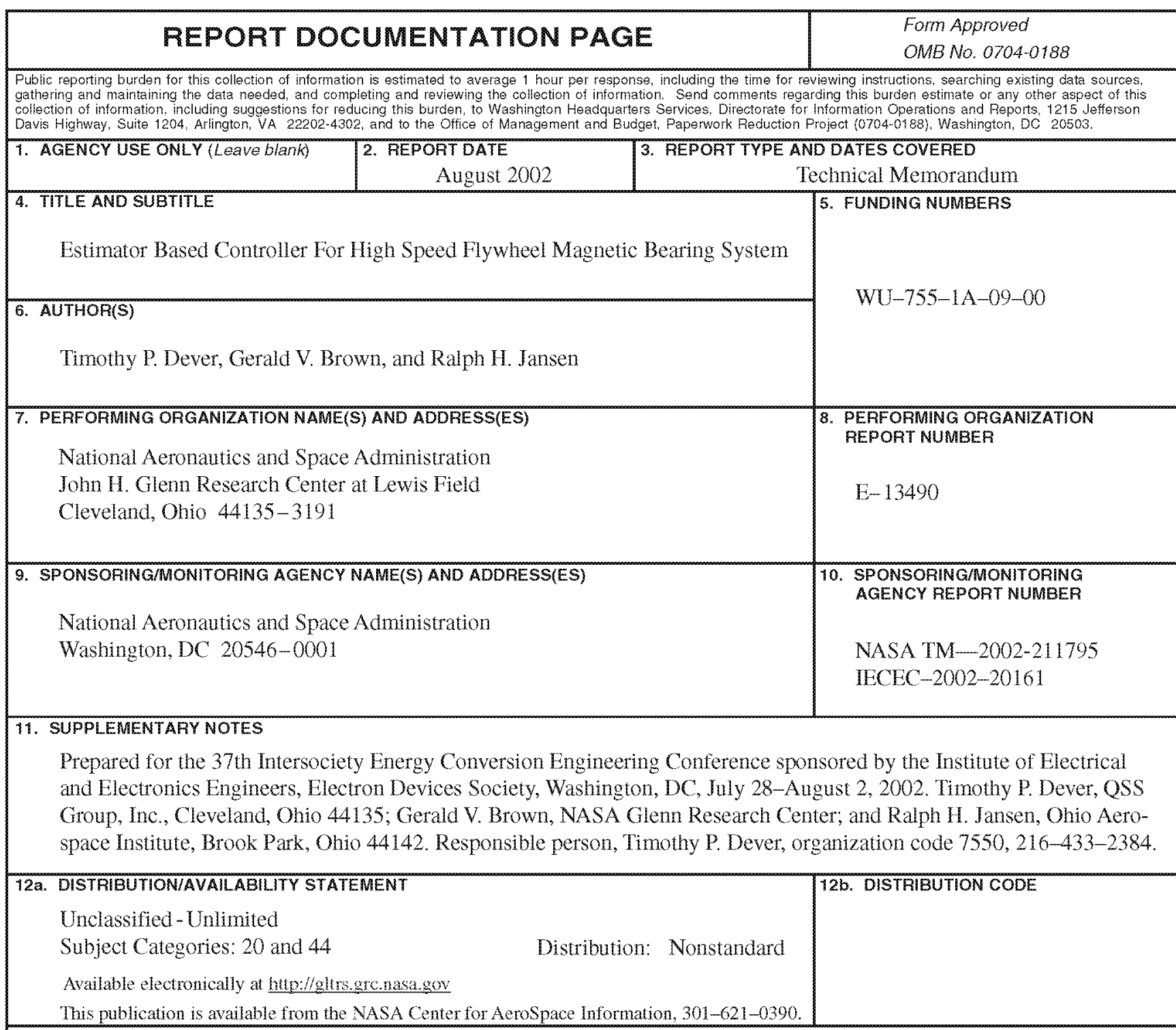

13. ABSTRACT (Maximum 200 words)

A flywheel system and its operator interface are described. Measurements of magnetic bearing negative stiffness are performed. Two digital magnetic bearing control algorithms (PD and estimator based) are defined and their implementations are described. Tuning of each controller is discussed. Comparison of the two controllers' stability, damping noise, and operating current are described. Results describing the superiority of the estimator-based controller are presented and discussed.

\begin{tabular}{|c|c|c|c|}
\hline \multirow{2}{*}{\multicolumn{3}{|c|}{$\begin{array}{l}\text { 14. SUBJECT TERMS } \\
\text { Flywheel; Magnetic bearing; Controller; Estimator }\end{array}$}} & \multirow{3}{*}{$\begin{array}{l}\text { 15. NUMBER OF PAGES } \\
\frac{12}{\text { 16. PRICE CODE }} \\
\text { 20. LIMITATION OF ABSTRACT }\end{array}$} \\
\hline & & & \\
\hline $\begin{array}{l}\text { 17. SECURITY CLASSIFICATION } \\
\text { OF REPORT } \\
\text { Unclassified }\end{array}$ & $\begin{array}{l}\text { 18. SECURITY CLASSIFICATION } \\
\text { OF THIS PAGE } \\
\text { Unclassified }\end{array}$ & $\begin{array}{l}\text { 19. SECURITY CLASSIFICATION } \\
\text { OF ABSTRACT } \\
\text { Unclassified }\end{array}$ & \\
\hline NSN $7540-01-280-5500$ & & & $\begin{array}{l}\text { Indard Form } 298 \text { (Rev. 2-89) } \\
\text { scribed by ANSI Std. Z39-18 } \\
-102\end{array}$ \\
\hline
\end{tabular}

